\title{
RESEARCH MOVEMENTS AND THEORIZING DYNAMICS IN MANAGEMENT AND ORGANIZATION STUDIES
}

\begin{tabular}{|c|l|}
\hline Journal: & Academy of Management Review \\
\hline Manuscript ID & AMR-2018-0466-Original.R2 \\
\hline Manuscript Type: & Original Manuscript \\
\hline Topic Areas: & $\begin{array}{l}\text { Actor-Network theory, Philosophy of science and/or sociology of } \\
\text { knowledge, Power and Resource Dependence }\end{array}$ \\
\hline Political dynamics in change < Organizational Development and Change \\
\hline Abstract: \\
& $\begin{array}{l}\text { In this article we propose a conceptual model of the processes that } \\
\text { regulate theory selection and retention in Management and Organization } \\
\text { Studies. Considering the many sources of theoretical variety that } \\
\text { characterize our field, what requires explanation is both the proliferation } \\
\text { of theories as well as the decline of some schools of thought. We argue } \\
\text { that research programs (ordered sequences of theories) lose momentum } \\
\text { when the research movements that develop and maintain them fail to } \\
\text { attend to some organizing priorities. By conceptualizing theorizing as } \\
\text { form of organizing, we describe how research movements dynamically } \\
\text { arrange sociomaterial elements (grammars, thought styles, material } \\
\text { artefacts and empirical craft), arguing that their sustainability depends } \\
\text { on their capacity effectively to navigate the paradoxical tensions that } \\
\text { derive from these organizing efforts. }\end{array}$ \\
\hline
\end{tabular}


RESEARCH MOVEMENTS AND THEORIZING DYNAMICS IN MANAGEMENT AND ORGANIZATION STUDIES

\author{
Stewart Clegg \\ University of Technology Sydney ${ }^{1}$
}

Miguel Pina e Cunha

Nova School of Business and Economics

Marco Berti

University of Technology Sydney

\footnotetext{
${ }^{1}$ Stewart Clegg is also affiliated with Nova School of Business and Economics

${ }^{2}$ Miguel Cunha acknowledges that this work was funded by Fundação para a Ciência e a Tecnologia (UID/ECO/00124/2019, UIDB/00124/2020 and Social Sciences DataLab, PINFRA/22209/2016), POR Lisboa and POR Norte (Social Sciences DataLab, PINFRA/22209/2016)
} 


\title{
RESEARCH MOVEMENTS AND THEORIZING DYNAMICS IN MANAGEMENT AND ORGANIZATION STUDIES
}

"We cannot improve the theorizing process until we describe it more explicitly" (Weick 1989, p. 516).

\begin{abstract}
"No canon, no collective, no institution can go outside itself to a world of independent objects for criteria of knowledge, since there is no other way except by its own rules to describe what's being done with regard to knowledge.” (McHugh 1970, p. 335)
\end{abstract}

\begin{abstract}
In this article we propose a conceptual model of the processes that regulate theory selection and retention in Management and Organization Studies. Considering the many sources of theoretical variety that characterize our field, what requires explanation is both the proliferation of theories as well as the decline of some schools of thought. We argue that research programs (ordered sequences of theories) lose momentum when the research movements that develop and maintain them fail to attend to some organizing priorities. By conceptualizing theorizing as form of organizing, we describe how research movements dynamically arrange sociomaterial elements (grammars, thought styles, material artefacts and empirical craft), arguing that their sustainability depends on their capacity effectively to navigate the paradoxical tensions that derive from these organizing efforts.
\end{abstract}




\section{INTRODUCTION}

Theory building has been described as an evolutionary process including variation, selection and retention (Weick 1989). In Management and Organization Studies (MOS) much attention has been given to 'variation', which has been attributed to a number of factors. In MOS there are multiple paradigms grounding different theories (Burrell \& Morgan 1979; Gioia \& Pitre 1990; Sandberg \& Tsoukas 2011) and to frequent borrowing from other disciplines (Oswick, Fleming, \& Hanlon 2011). The term 'theory' is seen as part of the problem, affording multiple meanings (Abend 2008; Suddaby 2014). The popularity of various theories and their meanings, in turn, are seen to be unduly influenced by fads and fashions (Abrahamson 1991; Bort \& Kieser 2011). In this paper we propose understanding theory as constituted by texts formulating an abstract statement of relations in an argument that is engaged with competing theories and that addresses empirical practices.

We know from the philosophy of science that research programs (organized sequences of theories) are resistant to straightforward empirical refutation, since their conceptual 'hard core' is protected by a belt of 'expendable' auxiliary hypotheses, as Lakatos (1978) argued, adding to Popper's (1959) falsifiability criterion. Additionally, there have to be rival theories developed that can provide better explanation of the contested issues. Representing the field of theory as a competition in which, depending on the mix of criteria, only the fittest survive, has a clear Darwinian echo. Less clear is what determines theory retention: why do certain theoretical perspective persist and evolve, while others lose traction, especially given that the assumptions bounding each theory (Bacharach 1989) vary across alternative paradigms and disciplines? While theories can be 'problematized' (Alvesson \& Sandberg 2011) by challenging their postulates, this operation is always framed from within a set of epistemological and ideological orientations. In science, a plurality of theory entails a plurality 
of rival hard cores to protect in the tournament of ideas, which takes place as revolutionary moments marked by incommensurable paradigms (Kuhn 1970).

Kuhn's (1962) ideas, when translated into MOS by Burrell and Morgan (1979), lost their evolutionary momentum, becoming atemporal as the incommensurability of rival paradigms was stressed in a move to make space for more plural approaches. The subsequent development of MOS in the past forty years attests to a great degree of plurality across the field. Various voices lament the consequences of excessive theoretical proliferation that has occurred in MOS subsequently (Davis 2010; Grandori 2001; Pfeffer 2007). Nonetheless, our discipline is a dynamic field, which transforms as the vitality and influence of different theoretical approaches waxes and wanes. Once leading approaches, such as contingency theory (Burns \& Stalker 1961; Donaldson 2001; Lawrence \& Lorsch 1967) lose influence, despite attempts at revival (Qiu, Donaldson, \& Luo 2012). Theories' vitality and capacity to attract scholarly interest decline with the lack of evolution in new directions. Over the past forty years contingency, population ecology and institutional theories jostled for dominance, with institutional theory gaining current ascendancy. These theories not only strive to represent reality but also performatively shape practices (D’Adderio \& Pollock 2014; Garud, Gehman, \& Tharchen 2018; Marti \& Gond 2018). Diverse theories organize phenomena differently and thus are powerful in their effects (Foucault 1977, 1980).

The research question we pose is why do some MOS theories decline and others persist and what are the dynamics of theorizing by which some theories lose momentum, exhausting their vitality and capacity to contribute to the practice of theory? The activity of theorizing (D'Adderio, Glaser, \& Pollock 2019; Weick 1995b) is a social process, implicating power struggles, organizing and informal practices (Frickel \& Gross 2005; Kuhn 1970; Lamont 2009), as well as tacit knowledge (Michailova et al. 2014). The practice of theorizing entails the 
creation of instruments for data collection, creating artefacts to be analyzed though a formal theoretical language (Hambrick 2007; Pfeffer 2014; Van Maanen 1989). These practices, when displayed in public, become objects for promotion and discussion in journals, faculties and conferences. We build on Lakatos (1970) idea that theories should be considered as components of a research program, sharing a common 'hard core' of principles that cannot be renounced without abandoning the program altogether. Research programs exclusively concerned with exploiting their conceptual hard core degenerate, while vital ones carefully manage to develop and extend the core (Lakatos 1970, 1978).

We expand this perspective by considering the role of research movements, the sociomaterial assemblages constituted and maintained through organized collective action (Frickel \& Gross 2005) that produce and support research programs. We thus consider theorizing practices as organizing not just ideas, observations and methods but also people, material artefacts and discourses. We argue that success or decline of a research program in MOS depends on the capacity of the research movement supporting it to attend to some fundamental organizing priorities: community boundedness, practices of intellectual craft, modes of heuristic regulation and achieving research impact. To be sustainable, research movements need to implement effective strategies to navigate tensions entailed in each organizing process. Respectively, we see these tensions as those of openness/closure; novelty/continuity, and rigor/applicability.

We substantiate our argument in the following way. First, we argue that theorizing socially constructs a stock of knowledge posited as being of explanatory and generative value (Van Maanen 1995). Conceiving of theorizing as a form of organizing allows consideration of both the product of its activities (theory) as well as the practices enabling accumulation of intellectual capital and social legitimation as science. Second, we note how all research 
programs (Lakatos 1978) must navigate a tension between centripetal forces (defending their conceptual cores) and centrifugal ones (expending the reach of the programs). Third, we introduce the key idea of a research movement, the sociomaterial assemblage that maintains and reproduces research programs. Fourth, we delineate what we take to be the constitutive components of such a movement (theoretical grammars, thought styles, empirics and actor networks). Fifth, we identify organizing priorities and paradoxes in research movements, conceptualized in terms of four practices: community boundedness, intellectual craft, heuristic regulation and research impact. Sixth, we elaborate how the interrelatedness of these practices gives rise to paradoxical tensions. Seventh, we elaborate strategies that research movements use in navigating these tensions (separation, oscillation and transcendence). We submit that these dynamics of theorizing lead to selection/retention of research programs, maintaining or eroding their vitality. Exemplary cases from the history of MOS illustrate and ground our explanatory model. Finally, we move to our discussion and conclusion, in which the nature of our contribution is reiterated. In a nutshell, it consists of using organization studies constructs to explain organization theorizing as practices of organizing priorities and research movements, in terms of their constitution and interrelatedness through practices and strategies devised to navigate the tensions that these processes generate.

\section{THEORIZING AS ORGANIZING}

\section{What is science?}

What is science? We regard it as an organizing practice that socially constructs a stock of knowledge taken to be of explanatory and generative value (Cannella \& Paetzold 1994; Frickel \& Gross 2005; Kuhn 1970). Its product, theory, is a coherent body of statements, methods and models describing phenomena, fruit of an intersubjective agreement achieved though language, ritual, categories and classification. Organizing practices work with "empirical material [that] 
is an artefact of interpretations and the use of specific vocabularies" (Alvesson \& Kärreman 2007, p. 1265). These organizing practices bear traces of historical and institutional processes producing consensus and conflict about which theorizing and research practices afford most value (Callon 1995; Latour \& Woolgar 1979). The multiple usages of the name 'theory', which can refer to a set of general propositions, an explanation of phenomena, a conceptual perspective, an interpretation of texts, a normative position, etcetera (Abend 2008), illustrate the ongoing process of social construction that is implicit in theorizing. Theories, similarly to other complex ideas, are rarely an individual but invariably a collective achievement, being produced in a dialogic relationship involving ideas, idea-makers and idea-users (Coldevin et al. 2019), engaging diverse subjects (Pickering 1993) capable of resisting as well as accommodating specific inclusions and exclusions.

Some recurrent concerns about how and what to include or exclude see some scholars stress prioritizing theorizing over reporting the 'facts' of data (Birkinshaw, Healey, Suddaby, \& Weber 2014; Hambrick 2007) as a mark of scientific legitimacy (Flyvbjerg 2001; Ghoshal 2005; Hambrick 2007). In consequence, differing theoretical 'language games' (Wittgenstein, 1958) ensue. Their fecundity is seen to hinder knowledge development (Pfeffer 1993), 'balkanizing' the field (Grandori 2001), cluttering it with too many ideas (Pfeffer 2014). The debate between 'theoreticians' and 'empiricists' is ongoing (Davis 2015; Lounsbury \& Beckman 2015). Empiricists are charged with using observational data "as mirrors of reality" (Alvesson \& Gabriel 2013, p. 255) and their differences with the theory geeks are satirized as the Lilliputians' trivial but ferocious diatribe between 'big' and 'little-enders' (Reed \& Burrell 2019). Alternative paradigms are underpinned by incompatible frames for interpretation (Weaver \& Gioia 1994), making it difficult to settle disputes (Cannella \& Paetzold 1994). Some voices celebrate and defend this polyphony, treating as a sign of pluralism and fertility (Reed \& Burrell 2019; Van Maanen 1995). Others criticize pluralism, attributing it to the lack of 
confidence of an immature discipline, by promoting unification under one paradigm (usually that to which they adhere) (Donaldson 1995; Pfeffer 2014). Closing ranks, unifying under a dominant paradigm, becomes the rallying call (Donaldson 1996; Pfeffer 1993; Pfeffer \& Sutton 2006), which would require scholars whose careers and reputation were built on a less favored paradigm to 'liquidate' their intellectual capital. Given the time spent investing in intellectual capital as well as the subsequent illiquidity of these as marginal investments, liquidation is less likely than struggle. These are the tensions that give rise to centripetal and centrifugal tendencies in MOS science.

\section{Research movements and centripetal and centrifugal tensions}

Lakatos proposes that change and development in theories can be understood only if we do not regard individual theories as abstract statements of relationships so much as organized sequences. Research programs are characterized by a central set of assumptions, constituting the hard core, around which tacit consensus is built that is relatively resistant to refutation, being protected by a "negative heuristic" which tells what paths of research to avoid (Lakatos 1970, p. 191). Criticism and empirical refutation are concentrated on the "protective belt of auxiliary hypothesis which ... bear the brunt of test and get adjusted and re-adjusted or even completely replaced" (1970, p. 191). Research programs can be progressive, making novel predictions possible, or degenerative, continuously producing ancillary hypothesis that do not help to understand new phenomena so much as defending the hard core by justifying unexplained data. These opposite forces are in an interdependent relationship that determines the vitality of any paradigm. Attempts to falsify the conceptual core of a theory empirically can be thwarted by recurring to "some auxiliary hypothesis or by a suitable reinterpretation" of its terms (Lakatos 1970, p. 182).

We employ the term research movement to describe the sociomaterial assemblage (made up of 
researchers, methods, theories, research centers, publication outlets, software and other actants) that - through its organizing - supports knowledge production. It is within research movements that the tensions between centrifugal and centripetal forces become salient. Where there are competing theories, without some counterbalancing factors, centrifugal forces can splinter a discipline into countless 'schools of thought' or 'paradigms'. We need to consider what the dynamics are that enable a degree of stability and homogeneity in theorizing, since the capacity to build consensus, a "social justification of belief" (Rorty 1979, p. 170), is essential for the maintenance and diffusion of a theoretical perspective. "Both centripetal and centrifugal forces fuel theory development" (Schad, Lewis, \& Smith 2019, p. 4); the former allows the establishment of a common grammar, while the latter drives expansion and development, provoking debates that are useful both to clarify conceptual boundaries and to spark new insights.

Centripetal forces solidify theorizing as a zone of concordance, establishing the assumptions, vocabularies, grammars and principles that bound each paradigm. Centripetal forces cluster theories around coherent research programs (Lakatos 1970, 1978), creating research movements that tend to develop fixed repertoires of highly reproducible routines due to pressures to perform reliably and be internally consistent, which determine a degree of inertia that restrains change (Hannan \& Freeman 1984). The 'core' aspects of research movements are particularly subject to organizational inertia; this is both a positive survival trait, enabling program reproducibility, thanks to (methodological) reliability and (program members') accountability, while it can also be a constraint, limiting innovation (Hannan \& Freeman 1984). The relations between the elements making up the outer ring of centrifugal tendencies are pulled towards concordance by centripetal institutional pressures arising from the relations between the elements. To articulate the different paradoxical tensions that emerge from the need to navigate this central opposition between centrifugal and centripetal forces and the 
consequent need to navigate them to preserve resarch program vitality, in the next section we consider the four sociomaterial components that, combined, enable and constitute theorizing within a research movement, highligting the specific tensions generated by their coupling.

\section{COMPONENTS CONSTITUTING RESEARCH MOVEMENTS}

We identify four essential elements that contribute to the centripetal and centrifugal organization of a research movement in MOS that, combined, allow the enactment of the four organizing and sense-making processes necessary to this collective heuristic effort (Fig.1).

\section{Theoretical grammars}

Theorizing conceptualized as a social activity (Callon 1995) requires a shared grammar rather than singular individuality in creative processes (Garud, Gehman, Kumaraswamy, \& Tuertscher 2017; Mueller \& Whittle 2011). The notion of grammar indicates the specific languages adopted within a research movement to identify key concepts and correct ways to relate them, in line with a coherent set of ontological and epistemological assumptions, objects of study, and heuristic purposes. Grammars serve as organizing devices for achieving social agreement about the nature of things being discussed, both within the scholarly community and broader society (Frickel \& Moore 2006). Different grammars signal "the values upon which that knowledge is built" (Suddaby 2014, p. 407).

Theoretical grammars derive from language games in which language is interwoven with action, with meaning deriving from the rules of the game being played (Wittgenstein 1958). As a consequence, different idiomatic ways of thinking and arguing develop to support theoretical claims (Cornelissen 2017, p. 2), each implying different metaphorical associations (Cornelissen 2005; Morgan 2006), reflecting different ideas about how sound knowledge can be produced (Boxenbaum \& Rouleau 2011). Grammars become embodied, embedded and 
embrained. Embodied in the process of writing and citation, the naming of names, the indexing of this rather than that community of practice; embodied grammars also materialize as repertoires of buzzwords that support the 'brand strategy' of a research movement (Mehrpouya \& Willmott 2018). Theorizing is embedded because its language is socially constructed and situated as sensemaking developed by a community of practice in which scholars create distinct co-citation networks (Üsdiken \& Pasadeos 1995). Theorizing is embrained, because as Lakoff and Johnson (1980) argue, customary metaphors of theorizing become fused in neural pathways to which cognition defaults. For instance, if the notion of causality is invariably associated with the interaction of coterminous variables in the same space and time, on a simulacrum of the experimental method, then it becomes difficult to entertain notions of ontogenetic causality embedded in the nature of things (Bhaskar 1975 [2008]), or that is historically genealogical (Pezet 2012). Metaphors that the use nouns produce structure while verbs reveal processes (Bakken \& Hernes 2006): thus grammar can reveal different ontological positioning.

The grammar of theorizing has performative effects shaping the 'objects' depicted (D'Adderio \& Pollock 2014; Marti \& Gond 2019). For example, what scholars of organizational culture describe as 'basic assumptions' become, for Foucauldian discourse analysts 'dominant discourse statements' while, for neo-institutional theorists they are 'schemas' and 'scripts'. Analogously, different research movements use similar terms to identify separate phenomena: examples include discourse (Alvesson \& Kärreman 2000), power (Fleming \& Spicer 2014), performativity (Gond, Cabantous, Harding, \& Learmonth 2016), routines (Parmigiani \& Howard-Grenville 2011). 


\section{Theoretical thought styles}

Thought styles is a concept that derives from Fleck (1935 [2012]). Fleck used the concept of 'thought collectives', or 'thought worlds' as they were labelled by Douglas (1986), to describe those who share a thought style to explore "shared meaning through notions of thought collectives and thought styles, examining the work of scientists and the production of scientific knowledge" (Logue, Clegg, \& Gray 2016, p. 6). Scientific work is characterized by a "tradition of shared assumptions, which are largely invisible to members and thus are rarely questioned." (Logue et al. 2016, p. 6). Each research movement has a thought style "which leads perception and trains it and produces a stock of knowledge" (Douglas 1986, p. 12). The stress is on shared intersubjectivity as a cognitive trait.

Social organization shapes thought style, in terms of repertoires for human cognition, which became a core element in Douglas' $(1966,1970,1986)$ ideas (Logue et al. 2016). Thought styles encapsulate a process in which knowledge is shaped, silencing some approaches and giving relevance to others. Thought styles make sense of the flow of experiences as something collectively enacted (Schütz 1945; Weick, Sutcliffe, \& Obstfeld 2005) through shared language in terms of concepts, rituals of citation of particular works, the deployment of common categories and classifications as socially constructed facts. Thought styles, such as institutional theory (DiMaggio \& Powell 1983), and its subordinate networks of institutional logics (Thornton, Ocasio, \& Lounsbury 2012), institutional fields (Zietsma, Groenewegen, Logue, \& Hinings 2017) and so on, embed and reproduce consensus about knowledge. In addition to common interpretive schemas, the members of a research movement are likely to share normative beliefs providing value-based rationale for action (Hassard \& Wolfram Cox 2013). For example, contingency, resource-based or transaction cost theorists are likely to disagree 
with labor process or critical management scholars on what constitutes "bigger, better and more challenging” (Birkinshaw et al. 2014, p. 38) research questions.

As an antecedent idea Fleck's thought styles bear similarity to several subsequent core concepts used in discussions of the social organization of science. Frickel and Gross (2005) refer to Scientific Intellectual Movements to indicate "collective efforts to pursue research programs or projects for thought in the face of resistance from others in the scientific or intellectual community" (2005, p. 206). In the context of MOS, the concept of successful "schools of thought" (McKinley, Mone, \& Moon 1999, p. 634) has been used, where success is attributed to a capacity to combine novelty and continuity within a sufficient broad scope of application, allowing adoption and empirical validation which drive legitimacy (McKinley et al. 1999).

\section{Theoretical empirics}

Theoretical empirics also play a role. The assumptions and principles bounding each research program will imply 'privileging' certain empirical objects (and will even contribute to shaping them). Empirical objects achieve their status as interesting not because of any intrinsic objective features they possess but as a result of their being theorized as empirical objects. For instance, the Aston School (Pugh \& Hickson 1976) constituted some elements from within Weber's (1922 [1978]) dimensions of bureaucracy as structural variables of organizations. Subsequently, Foucault (1977) focused on disciplinary power, a concept not too far removed from Weber's disciplinary systems of knowledge. Had the developments of the Aston School taken place in the late 1970s rather than the early 1960s it may well have been the case that the notion of disciplinary knowledge would have played a role. In the early 1960s the empirical object of disciplinary practices had no particular theoretical status in MOS. It took Foucault's work for it to become considered by some theorists (Clegg 1989b), while others decided to remain faithful to the entrenched perspective which 'naturalized' organizational structures 
(Donaldson 1987). Similarly, Weber's discussion of contract as a basis of organization structure was interpreted strictly in terms of contracts of employment as the measure of organization size. By the turn of the century, after the widespread development of contracting out (Kolpakov \& Anguelov 2020) and supply chains (Vonderembse, Uppal, Huang, \& Dismukes 2006), the notion of contract would likely have been rethought to include forms other those of individual employment.

Empirical objects both inspire and anchor theory. Theories provide an analytical system linking “different concepts in order to explain or predict empirical phenomena" (Marti \& Gond 2018, p. 489) that are intimately connected with empirical reality (Eisenhardt 1989), leading to predictions that can be falsified or verified, even if they cannot be definitively 'proven' (Shapira 2011). At the same time empirical material should be considered a "critical dialogue partner" rather than a determinant of theory (Alvesson \& Kärreman 2007, p. 1266), since knowledge is socially constructed: "strictly speaking, there are no such things as facts" (Schütz 1953, p. 22) outside of the practices that enact them as such. Researchers are not 'objective' interpreters: equivalence between facts, signs, accounts is never perfect, so data is always fused with theory (Alvesson \& Kärreman 2007).

\section{Theoretical actor networks}

Theoretical actor networks (Callon 1995) may be defined as constantly shifting networks of relationships between objects, concepts, processes, materialities and humans. They are dissimilar to thought styles because the networks may include relations that are simultaneously material (between things) and semiotic (between concepts), rather than being intersubjective. Observations are conducted through specific tools (e.g. a survey, a field note, a performance metric), through which phenomena are translated into inscriptions; these inscriptions are edited to become data, that are then collated and framed into theories. The correspondence between 
theory and observed reality is achieved through a process of translation that "also implies betrayal" (Law 2008, p. 144). Considering the role of actor networks acknowledges the role of material, nonhuman agency in scientific inquiry, as not all choices can be attributed to purposeful choices by individual scholars (Pickering 1993). For example, the dynamics of publishing 'games' (Broad 1981; Gabriel 2010), which embed further games such as reviewing, have elements of randomness (Starbuck 2005). Moreover, technical constraints and opportunities, such as the affordances of technologies used for collecting and analyzing data, searching and accessing sources, writing and publicizing studies (conferences, publications, online repositories etc.) are major actants in constituting theoretical actor networks. For instance, comparison of two randomly selected issues of AMR (a pre and post- internet one) shows that the number of sources cited in articles has remarkably increased. We counted the number of sources included in the reference lists of the first 5 articles from a randomly selected 'old' issue (April 1989), comparing them with the ones included in a more recent one (April 2019), revealing a $64 \%$ increase in the average number of cited sources ( 73 versus 120$)$. The notion of actor network also highlights the practical, situated character of collective idea work (Carlsen, Clegg, \& Gjersvik 2012; Coldevin et al. 2019) that implies an entwinement between agents and the sociomaterial reality in which they are immersed (Heidegger 1927).

Insert Fig 1 About Here

\section{ORGANIZING PRIORITIES AND TENSIONS IN RESEARCH MOVEMENTS}

The four elements outlined interact in shaping four organizing practices and processes that constitute and maintain research movements. These four organizing priorities preserve vitality, 
success or decline of a research movement in MOS while navigating the tensions entailed in exploiting existing theory and exploring new theory. These priorities, we shall argue, are practices of community boundedness (openness/closure), practices of intellectual craft (novelty/continuity), practices of heuristic regulation (rigor/applicability) and practices for research impact (representation/performativity).

Four ideal-typically distinct but practically overlapping organizing priorities need to be attended to and governed in order to preserve cohesion and identity in a research movement. (Fig.1). Failing to maintain coherence in these areas would imply not only a loss of vitality in the research movement but its collapse, producing fragmentation or loss of legitimation. Automatic refutation of theories generated in the past does not necessarily follow. What is important is the presence or absence of an organized community supporting and enriching these theories, actively defending and expanding the conceptual hard core of the research program. Defense and expansion occur through developing and promoting new ancillary hypotheses, in the absence of which theories become more vulnerable to attack or simply fall into oblivion, overshadowed by more novel research programs, supported by more vital, visible and influential research movements. Each organizing priority implies a specific tension (Fig.1), a set of interdependent and persistent contradictions that cannot be 'solved' but only navigated, 'worked through' in practice (Smith \& Lewis 2011).

\section{Practices of community boundedness: the openness-closure tension}

The organizing priority of community boundedness concerns the 'maintenance' of the academic network and the broader community of practice (involving also students, practitioners and sponsors). These are all directly involved in the development, study and application of the theories generated under the aegis of the research movement. Organizing community boundedness occurs at the intersection of intersubjective agreements and actor 
networks, since it requires both social and material elements. It includes producing and testing theories within a research program, as well as socializing new scholars to the movement, attracting financial resources, promoting and publicizing its 'brand' (Mehrpouya \& Willmott 2018). The outcome of this organizing is not a formal structure, nor does it imply clearly set and policed boundaries but involves the existence of liminal zones between fields of inquiry (Hassard \& Wolfram Cox 2013). Some scholars build a profile as knowledge brokers, participating in different research movements, while others prefer investing most of their energies in a single research program. Yet, all scientific movements are episodic, existing only for finite periods (Frickel \& Gross 2005). Consistent investments in fostering and supporting organized collective action (researching, teaching, editing, conference organizing, workshopping, etc.) oriented to theorizing aligned with a specific research program is a precondition of sustenance. These are necessary to replenish the ranks of senior scholars that fade away. Sometimes, in the absence of past charismatic anchors, research movements diminish fast.

Inclusion and exclusion from any body politic is the fundament of sovereignty, which is why borders assume such significance in national politics. The body politic is not only to be found at the national level; any association with membership rules, whether explicit, implicit, constitutive or preferential may be said to be a body politic. If this is the case with a golf club or trade association it is no less the case for a research community. All research communities have a politics of recognition and non-recognition of what being in and out of the fold of membership entails. In organization theory we refer to these as power dynamics (Clegg 1989a). Power dynamics assume particular relevance when attending to the organizing priority of community boundedness. Boundedness does not just refer to formal membership; it "traverses and produces things, it induces pleasure, forms of knowledge, produces discourse" (Foucault 1984, p. 120), it creates belonginess. 
Collective acceptance is contingent on the interaction between thought styles and actor networks. Collective acceptance is signaled through esteemed journal publication, a process of many random contingencies but which is, nonetheless, an 'obligatory passage point' to being fully recognized. These contingencies include matching a journal's keywords to the thought styles informing the paper; the citation of the 'usual suspects' that display affinity with these thought styles; the appreciation by the managing editor of the appropriate actor networks with elective affinities to these thought styles, as well as the more usual matter of substance, methods, etc. Such a situation produces multiple tensions. For instance, the review process operates on a "principle of exclusion and segregation" meant to protect the health and integrity of the intellectual field against abnormal elements (Foucault 1984, p. 61). The review gatekeepers exercise the sovereign right to kill ideas in the name of the health of the intellectual field as a whole. Together with the right to kill, however, there is a duty of care of researchers (Schwarz, Cummings, \& Cummings 2017), a curatorial role that the journal editor strives to articulate. The opposition between these tendencies to kill and to care can become manifest as when there is a tension "between theory as a device for knowledge production and its role in legitimating the jurisdiction of professional expertise" (Suddaby 2014, p. 409): does the paper constitute new knowledge or merely add to the sum of existing knowledge? Likewise, there may be a tension between care for the intellectual field and desire for peer recognition (Schwarz et al. 2017): intellectual dues may be redeemed or not, with the latter judgment being the killer.

Tensions such as those discussed above engage a world of thought styles with the actor networks informing the world of the researchers as authors and the world of the researchers as reviewers. The more tightly constrained these inter-relations are the greater the chance of winning in the publication, or in the research-grant acquisition games. It pays to know which actor networks and thought styles are in play for both reviewers and researchers, if a large potential source of interpretive error is to be avoided. These tensions push towards paradigm 
conformance (closure). At the same time excessive closure can limit the capacity of a research movement to grow and remain vital, evolving a form of path-dependence that inhibits its development (Schad et al. 2019). Under these circumstances research movements can accept a degree of variance that allows for the development of new insights, instead of the generation of ancillary hypothesis aimed at protecting a static conceptual core (Lakatos 1978).

The dynamics of openness/closure not only affect the participants in the research movement but also concerns the scope of the research program, "the range of phenomena encompassed by the theory" (Bacharach 1989, p. 509). While a broad scope is thought to be a determinant of the sustained success of a school of thought (McKinley et al. 1999), expanding the range of a theory can be problematic, since it implies conceptual ambiguity (Astley \& Zammuto 1992). Ambiguity can be a resource for sensemaking, allowing multiple interpretations (Weick 1995a); however, it can also impact the identity of a research program negatively, causing splintering and secessions, as happened in organizational culture studies (Martin, Frost, \& O’Neill 2006).

\section{Practices of intellectual craft: the novelty/continuity tension}

Normative models prescribing the characteristics of 'good theory' typically list a number of attributes that theory formulations should possess. Achieving these characteristics is the essence of the intellectual craft that journal editors urge as good 'intellectual craftsmanship', (Mills 1980). Usually, these include parsimony (Bacharach 1989; Eisenhardt 1989), utility (Corley \& Gioia 2011; Davis 1971), clarity and specificity (Boxenbaum \& Rouleau 2011; Tsang \& Ellsaesser 2011), novelty and originality (Bacharach 1989; Corley \& Gioia 2011), generality and abstraction (Davis 1971; Sutton \& Staw 1995). Developing an organization theory that possesses all these desirable features appears not only difficult but impracticable because of trade-offs between abstract generalizability and detail (Bacharach 1989) and 
between generality, accuracy and simplicity (Weick 1979). Since "accurate-simple explanations say everything about nothing, general-simple explanations say nothing about everything, and general-accurate explanations say everything about everything but are unintelligible" (Weick 1999, p. 801), the directions are less helpful than might at first appear to be the case. Such trade-offs are not necessarily 'paradoxical' since they can be resolved by choosing a particular balance between the two (e.g. sacrificing the 'right' amount of accuracy to obtain the 'right' degree of generalizability).

Each research movement must, however, also cope with a more specific tension, deriving from another organizing priority: the need to regulate the assumptions, beliefs and normative principles that bound and direct theorizing within the movement. Normative regulation of intellectual craft occurs at the intersection of thought styles and grammars. Values consensually shared by a community (for example privileging critical or performative concerns in organizational inquiry; pursuing equilibrium or advocating disruptive transformation; favoring micro, meso or macro perspectives etc.) underpin the choice of assumptions and perspectives. Organization theories gain strength by articulating selection rules and by artificially isolating social entities, fabricating distinctions and creating differences. These assumptions become embedded and reproduced in crafting conventional language games and accepted grammars as a selectivity driven by specific interests, values and political intents (Flyvbjerg 2001).

The tension between novelty and continuity entails maintaining enough of the former to fuel interest, while avoiding straying too far from existing conceptions (McKinley et al. 1999). To be taken into account, authors need to join existing conversations (Lange \& Pfarrer 2017); to be influential they must present original ideas, with the potential "for changing the conversation" (Corley \& Gioia 2011, p. 27). Being interesting is a middle way between the feeling of absurdity that comes with being too novel and the boredom that comes with restating 
the obvious or the already-known (Davis 1971). The situation is similar to the problem encountered by new ideas and inventions: to be accepted, innovation must be located within the set of existing understandings and actions, while at the same time maintaining potential to allow the discovery of new possibilities of interaction (Hargadon \& Douglas 2001).

Different research movements will be driven by distinctive assumptions about the nature of organization, the purpose of organizational research, and what constitute 'relevance' or 'rigor' in research (Berti 2017). Hence, the definition of what constitutes an object of "tacit consent" or "common ground" (Lange \& Pfarrer 2017, p. 408) will vary across movements. Ideological rifts separate scholars who believe in the emancipatory purposes of organizational studies and those that promote its functional role in support of productivity and capitalism (Gioia \& Pitre 1990). Judgment of the appropriateness of the representation is not an objective assessment made possible by the existence of universal normative principles. Rather, it is the outcome of an agreement whereby different forms of craft work will assemble different assemblages of objects, thought styles and language games for different purposes.

While accepting that pluralism and enabling dialogue among different forms of theorizing might help overcome tensions arising from different crafts (Weick 1999), the consideration of the ideal attributes of any theory reveals a deeper tension, involving unstated background assumptions. Viewing a theory as a more coherent set of statements of relations explaining or predicting empirical phenomena (Corley \& Gioia 2011; Gioia \& Pitre 1990) implies privileging a conception of scientific rationality that views reality as a set of discrete entities separate from an observer capable of formulating a correct representation of them (Sandberg \& Tsoukas 2011). It is coherent with research programs that assume the role of science is to simplify complexity, by uncovering the basic rules underlying empirical variety (Simon 1962). Yet, in a different onto-epistemological perspective, social complexity neither can nor should be 
reduced. Instead, the role of theories is to aim either at complexifying understanding of reality (Tsoukas 2017) or fostering ethically preferable ways to organize (Flyvbjerg 2001).

\section{Practices of heuristic regulation: the rigor/applicability tension}

A third organizing priority for research movements concerns the need to regulate research activities. Situated at the intersection of grammars and empirical objects of studies, these regulation processes are meant to position a specific research movement in relation to tensions between practice and theory, between rigor and relevance (Berti 2017). MOS research and theorizing is often accused of being too abstract or circumscribed (Bennis \& O'Toole 2005), offering prevalently descriptive representations (Bazerman 2005) and producing theories that have little connection to practice (Peters \& Bogner 2002). At the same time, relevance is a highly idiosyncratic concept (Weick 2001), depending on an individual capacity to see possible connections (Paton, Chia, \& Burt 2013). Relevance also depends on fashions (Abrahamson 1991) and rhetoric (Sillince 2005), implicating an additional tension between acceptance and implementation.

Tension also exists between theorizing as a situated practical activity and theory as an abstract, timeless representation. In the latter, a legitimate contribution should ideally be complete, one that can both predict and explain the occurrence of phenomena (Bacharach 1989), as well as include description, explanation and boundaries/limitations (Whetten 1989). The exemplar for the completeness of theory is the language game of correspondence in which the formulations of the theory should model the relevant material attributes of the phenomena to which it refers. Concordance in correspondence signifies theoretical strength. Concordance is somewhat easier to attain when the materiality attended to cannot answer back in disagreement with the representations made, or learn from them, a situation that all social science researchers must face. 
These issues are common to all research movements in MOS and navigating them is essential for their sustainability. Each research movement will identify a specific set of heuristic regulation practices aimed at guaranteeing a satisfactory balance between rigor and applicability. These will be achieved in ways that are coherent with the assumptions and tacit agreements that underpin the movement and that shape its identity. For instance, even if individual scholars acknowledge the scientific validity of qualitative/idiographic accounts as well as quantitative/statistical studies, an audience of population ecologists it likely to consider absurd the attempt to contribute to their theorization with an ethnographic study. Postmodernists appear 'allergic' to propositional styles of theorizing favored by positivists while, conversely, positivists are quite capable of elaborating narrative accounts of alternative paradigms constituted as anti-management (Donaldson 1995).

Attempts at heuristic regulation result in wars of position between different research movements, competing for limited resources and attention. One theory (say paradox theory) can affirm itself by highlighting its contrasts with a previous theory (such as contingency theory) (Lewis \& Smith 2014). The contrast is important in establishing novelty and difference. Yet promising theorizing opportunities lie at the intersection of the paradigms. For example, some scholars have explored how paradoxical 'mindsets' are contingent upon culture (Keller, Loewenstein, \& Yan 2017; Peng \& Nisbett 1999) and others articulated contingency and paradox theories, showing that different paradoxical tensions emerge in various contexts which face different contingencies (Cunha et al. 2019). In other words, paradoxes may be viewed as depending on contingencies rather than existing outside contingency.

Research on teams suggests that teams need both differentiation and bridging or they risk losing opportunities for cross-fertilization (Ancona \& Bresman 2007). Bridging two fields can thus be more promising than splitting them. Different paradigms are cultivated in different moments 
by different scholars distinguishing themselves from other groups. Research movement teams' paradigm bridging may offend those most protective of the hard core on either side of the bridge. Bridging leads not to greater conformance but to innovation across boundaries that may be more or less sustaining of the innovation.

Tensions become manifest in implicit to calls to produce useful and 'evidence based' organizational theory (Bazerman 2005; Davis 2010; Pfeffer 2007). The aspiration for theoretical sophistication and objectivity in research practices clashes with achieving social acceptance in a practitioners' community. The thought styles and language games in which practitioners are engaged will usually be far from those of the theorists. The latter, engaged in a struggle for the riches of publication, citation and awards, compete in a market very different from that of practitioners' more immediate concerns. To connect with the thought styles encountered in the latter context entails buying into a language of commerce in which theories that 'win' in the marketplace for ideas model the intersubjective assumptions and language games embedded in the practices being attended to, thereby creating conditions that make them come 'true' (Ferraro, Pfeffer, \& Sutton 2005).

\section{Practices of research impact: the representation/performativity tension}

Research movements need to acquire and maintain legitimation, both in relation to their potential followers, as well as to other stakeholders on whose endorsement and active support their survival depends. Demonstrating the capacity to produce 'high-impact' research (Alvesson \& Sandberg 2013) is increasingly crucial for legitimizing a research movement. Opinions diverge on whether this impact should be primarily on management practice (Tushman et al. 2007), the stimulation of academic interest and discussion (Judge, Cable, Colbert, \& Rynes 2007) or the production of positive social outcomes (Antonacopoulou 2010). 
Impact clearly depends on audience. Suchman's (1995, p. 574) definition of legitimacy as "a generalized perception or assumption that the actions of an entity are desirable, proper, or appropriate within some socially constructed system of norms, values, beliefs, and definitions" applies also to actor network regulation. Key moments in which such judgements of legitimacy are regulated will be seminars, reviews, workshops, supervision of students and so on. This influential definition is not only useful in making an analytical point but also serves to illustrate it. The legitimacy of impact depends on audiences' 'generalized perception'.

Research programs as processes of social construction can enable performative impact by produce new materialities as well as relabeling old constructs anew. Performativity refers to "the constitution of new worlds through their articulation" (Garud \& Gehman 2019, p. 680). For instance, chemistry will create new materials and compounds the properties of which become further object of study, while economics' constructs produce concrete effect on the economy (Callon 2007). The existence of performative effects is inherent to any use of language (Austin 1962), in that words are not simply used to indicate and represent but are sometimes used to produce social effects. In scientific disciplines, performative effects reach their apex in the case of Barnesian performativity (Barnes 1983), which become manifest when the application of a theory in practice results in the enactment of those processes that had previously only been depicted in theory (MacKenzie 2006). The acceptance of the model and its shaping of practice, such as agency theory (Fama \& Jensen 1983), becomes a recursive sign of legitimacy. What is afforded is correspondence from concepts to materialities, rather than the more conventional reverse.

A performative view "shifts the focus from linguistic representations to discursive practices" (Barad 2003, p. 807), helping to bridge the worlds of theory and practice. At the same time considering performative effects reveals a tension between organizational theory and 
organizational practices. When theories shape everyday language games, it is their recursivity that is simultaneously vital and unacknowledged. Recursivity generates a paradoxical situation: how is it possible to produce a "coherent description" (Gioia \& Pitre 1990, p. 587) of the social facts of 'new worlds' of materiality if both observation and theorizing affect and shape the nature of the phenomena in question? The success of a theory makes it so self-fulfilling that its statements become accepted as taken-for-granted truths (Marti \& Gond 2018), making the theory obvious, hence pointless. The theory's task is done; its vitality has been translated into everyday practice and language: indeed, much of strategy theory has precisely this quality (Clegg, Pitelis, Schweitzer and Whittle 2020, p.468). The phenomenon has practical effects: when a practice is legitimized and objectified as a 'best' practice it is more likely to be adopted but this ready acceptance reduces the critical capacity to adapt and modify that is required for successful implementation (Gondo \& Amis 2013). Another tension is implied, one that affects 'impactful theorizing', between the desire to disseminate only tried and true (evidence based) ideas and the demand of novel knowledge (Corley \& Gioia 2011).

Impact can lead to black boxing. Black boxing is defined by Latour $(1999$, p. 304) as "the way scientific and technical work is made invisible by its own success." When a device is performing efficiently or when a matter of fact is settled, the internal complexity of its processes is not a focus. As long as the transformation processes perform effectively, they will not be a matter for attention. "Thus, paradoxically, the more science and technology succeed, the more opaque and obscure they become". In the case of MOS, concepts such as 'institution' or 'dynamic capability' act as black boxes, exercising considerable power/knowledge effects. These effects are achieved by framing, in a collectively accepted way, bundles of data, interpretations, research practices, theories that make real their objects of inquiry, generating the phenomena they analyze. Thus, the actor network translations become embedded in grammars and influence the empirics. The identification of objects of inquiry (the empirics) of 
a research program, which is clearly important in defining audiences, does not involve just selecting some naturally existing objects. It also implies a degree of social construction, as some entities (e.g. a 'practice', an 'institutional field', a 'capability' etc.) are artificially 'carved' out of an interconnected social reality.

\section{STRATEGIES FOR NAVIGATING TENSIONS}

Organizational paradox theory (Smith \& Lewis 2011) maintains that, when faced with paradoxes, organizations that deny their existence, or try to cope with them with either/or choices (focusing only on one pole of the contradiction) will engender vicious circles. Vicious circles ultimately undermine organizational sustainability. In the case of research movements, choosing to deal with the paradoxical tensions identified in the previous section would ultimately degrade the viability of the movement, causing decline of its research program.

Excessive 'closure' causes stagnation in the pool of theorists, which reduces the capacity to generate novel ideas, causing a vicious circle. The existence of other successful research programs that performatively transform the object of study, making the theory less applicable (this appears to have been the fate of contingency theory) exacerbate the tendency. Conversely, too much opening will strain continuity and coherence, with negative impacts on rigor and loss of performative impacts. Similarly, an excessive focus on rigor (which also reinforces continuity) can reduce applicability, limiting the capacity to attract support and investments. On the other hand, being 'too practical' can minimize the 'representational' potential of a theory, making it self-fulfilling rather than 'influential', likely causing loss of legitimacy in the scholarly community.

In sum, lack of adequate management of the tensions inherent to organizing practices that sustain a research movement will ultimately cause it a loss of legitimacy. As legitimacy is a 
critical resource for the existence of any school of thought (McKinley et al. 1999), the mismanagement of tensions underlying theorizing will precipitate the decline of a research movement. Without constant support, even though developing new theories that can buffer and in some cases add to the conceptual core, the research program will progressively decay (Lakatos 1978).

By contrast, the generative potential of tensions can be harnessed by their acceptance and synergistic combination (Smith \& Lewis 2011). Finding ways of 'working through paradox' so as to displace them temporarily, allows for action (Smith 2014). Four fundamental strategies have been described in the literature: separation (Poole \& van de Ven 1989), oscillation (Smith 2014), transcendence (Abdallah, Denis, \& Langley 2011) and practical coping (Smets, Jarzabkowski, Burke, \& Spee 2015). We consider each of these strategies, showing how they can be applied to preserve the vitality of a research movement.

\section{Separation}

Separation can operate via temporization or spatialization (Czarniawska 2017), detaching contradictory elements in time or tasking them to different units (Tracy 2004); this strategy is frequently employed to tackle ambidexterity challenges in organizations (Papachroni, Heracleous, \& Paroutis 2016). In the case of theorizing this separation can be achieved by division of research labor within the same paradigmatic framework, with some research teams involved in expanding conceptual boundaries, occupying 'transition zones' towards other paradigms (Gioia \& Pitre 1990) or developing forms of meta-triangulation (Lewis \& Grimes 1999). 


\section{Oscillation}

Oscillation as variation in magnitude or position around a central point occurring in public (Smith 2014), opens the possibility of contradiction. Public contradictions can be managed through open discussion in conversational sparring sessions (Lüscher \& Lewis 2008). In theorizing circles, this is called a seminar; in more reflective practice it characterizes processes of peer review. Oscillatory strategies are particularly employed to manage practice/theory tensions that can be pointed out and traced in normative recommendations about how to produce 'good theory'. Together with the statement of general, abstract principles that should guide theory work, there are often references to 'craft' (Rindova 2008), tacit knowledge (Folger \& Turillo 1999), "art” (Byron \& Thatcher 2016), improvisation and bricolage (Boxenbaum \& Rouleau 2011; Van Maanen 1995). Hence, balance is found by referring to abstract principles while constantly embodying (through socialization, apprenticeship and lived experience both as researchers and as reviewers, editors and supervisors), the practical and ineffable elements of craft entailed in theorizing within specific actor networks. The creation of venues (e.g. conferences, workshops, journals) that allow both for this embodied learning and the transmission of general concepts becomes essential for building and maintaining theoretical vitality.

\section{Transcendence}

Transcendence refers to the capacity to move beyond oppositions by reframing the contradiction in a way that sees the opposites as mutually constitutive (Farjoun 2010; Lewis 2000). Transcendence is often achieved by means of rhetorical devices (Abdallah et al. 2011; Bednarek, Paroutis, \& Sillince 2017) and theorizing often has recourse to rhetoric to 'sidestep' some of the contradictions generated. For instance, the notion of 'reflexivity' (Hardy \& Clegg 1997; Hardy, Phillips, \& Clegg 2001) is often enrolled to transcend the contradictions between 
the social grounding and 'objectivity' ambitions of theories or to manage some of the contradictions that derive from the self-fulfilling characteristics of performativity.

\section{Practical coping}

It is well established that possibilities for meaningful action in practical coping with contradictions can be restored through micro-practices that help actors make sense of the situation, such as choosing which clothes to wear (Lê \& Bednarek 2017), employing irony and sarcasm (Jarzabkowski \& Lê 2017; Tracy 2004), or even making oneself scarce (Jarzabkowski \& Lê 2017). Micro-activities can also revitalize declining/declined theorizing. Examples would be when an established author ironically labels competing theories as anti-management (Donaldson 1995); when a strong theorizing community, such as that of institutional theory, is confronted with a possible midlife crisis (Alvesson \& Spicer 2018); when up and coming theorizing, such as, for example, paradox theory, is criticized for its premature aging (Cunha \& Putnam 2019). Ironical theorizing may prove a powerful lever for the advancement of MOS.

\section{DISCUSSION AND CONCLUSION}

In this paper we have argued that the capacity of research program (a coherent sequence of theories based on shared assumptions and perspectives) to persist over time is contingent upon the existence of a research movement, a group of scholars and institutions that is willing to develop new theories, preserving and adding to the conceptual core of the program. Such investment requires organizing four different elements: an agreement in thought styles about the meaning categories to be employed; a common 'grammar' specifying key concepts and ways to relate them; a privileged set of empirical objects of inquiry and an actor network incorporating human actors and non-human actants in research and theorizing activities. These different elements are analytically separable but interact in practice: some elements of actor 
networks become stable and embedded in grammars, while creating self-fulfilling prophecies in relation to empirics. Thought styles exhibit grammars and define the salience and relevance of certain empirical objects of study, contributing to the stabilization of networks.

Examining the interaction between the four components identifies four essential organizing priorities for any research movement: practices of community boundedness, intellectual craft, heuristic regulation and research impact. We have further argued that these organizing processes are bound to generate paradoxical tensions that need to be navigated in order to preserve sustainability of the research movement, avoiding a loss of legitimation that would undermine its capacity to attract further investments.

In a nutshell, we argue that - at least in the case of MOS - the unit of selection of theories is the way in which theories are created and supported, through theorizing, rather than some transcendental attribute of theories themselves. Practical consequences follow. First, if we want to assess the vitality of the theory, we should direct our attention to the sociomaterial assemblage that supports that theory (the research movement). It is the capacity of this 'informal organization' to manage a set of organizing priorities and to navigate their contradictions that determines the sustained success or decline of a 'school of thought'. The implication is that it is impossible to devise a set of metatheoretical methodological principles that can be used to assess theories independently from the frame set by their research program.

While some 'universal' principles exist that can be used to assess the quality of a theoretical statement (for instance, parsimony, coherence, falsifiability etc.) these are employed within the frame of reference (grammar, assumptions, black-boxes etc.) that defines and distinguishes the research movement that developed them. Each research movement will continuously 'maintain' the research program it expresses, by assessing, refining, rejecting theories (since this is one of the preconditions for their sustainability); however, this operation cannot be 
legitimately conducted by a follower of an alternative research movement. This does not mean that it is not possible or useful to use a problematization strategy to challenge the assumptions that bound a research program or a specific theory (Alvesson \& Sandberg 2011; Sandberg \& Alvesson 2011). Rather, we claim that a problematization strategy will - in most cases - add to another research program, rather than to the one being tested.

\section{Contribution to theory}

By stressing the sociomaterial components of theorizing activities we do not intend to question the usefulness of 'general', metatheoretical advice offered by many AMR editorials. The clarity, consistency and relevance of attempts to contribute to theory are invariably open to improvement, as our process of being reviewed illustrates all too clearly. ${ }^{3}$ Any research movement must make good use of such recommendations. Yet, in our discipline, because of the presence of different paradigms, heuristic frameworks, grammars and the performative effects of organizational theories, multiple incompatible theorizations that meet these 'technical requirements' can and do coexist.

Our model describes the social dynamics underpinning theorizing, offering an answer to our original research question: why do some MOS theories decline and others persist? The model extends the seminal contribution offered by Lakatos (1978), integrating it with more contemporary discussions from the sociology of science (Callon 1995; Frickel \& Gross 2005), which draw attention at the sociomaterial components of theorizing. Our model also extends that developed by McKinley et al. (1999) to describe the dynamics that allow for the persistence of schools of thought in organization theory. It also helps to make sense of the debate between

\footnotetext{
${ }^{3} \mathrm{We}$ are extremely grateful for the skilled and insightful review process curated by Udo Zander and conducted by the blind reviewers.
} 
proponents of paradigmatic unification in MOS (e.g. Pfeffer 2007) and advocates of pluralism (e.g. Reed \& Burrell 2019) as well as discussion of the production of 'non-sense' in organizational research (Bartunek 2020; Tourish 2020). Rather than 'taking sides' we articulate the reasons why these debates exist and will continue to do so in the future. While the central idea (the role of social dynamics in shaping scientific production) is rooted in a tradition that dates back to Kuhn (1970), our model allows for the integration of discursive, material and cognitive components of theorizing, highlighting the role of organizing practices and paradoxical tensions.

\section{Implications for (theorizing) practice}

By focusing on theorizing, researchers may approach tensions as fundamental to achieving both plurality and paradigmatic integration. Doing so makes a contribution that, in turn, reframes theory building from a concern with structure to process. In a structural view, researchers defend their research programs from other research programs by, for example, buffering the paradigmatic core with ancillary elements. In a process perspective, researchers integrate contradictory evidence not to defend their theoretical constructions but to renew their foundations through hybridization. Overall, the constant tension between conservatism and radicalism, consensus and dissent, order and disorder are critical to fuel the vitality and progressive nature of our discipline. It is the dynamism of debate that keeps hegemonies, with their calcifying effects, at bay. Our contribution helps to offer a more nuanced and dynamic view of the elements that produce successful theorizing as the interplay between plurality and paradigmatic integration.

In sum, this contribution will aid theorists in understanding what needs to be done to ensure a sustained return on their investment in theorizing as well as enable more critical reflection on the relationship between conceptualizing and the sociomaterial practices of grammars, thought 
styles, language games and actor networks. In our view, theorizing implicates all of these. At the same time, potential users of theories (students, managers and other organizational actors) can be made aware of the fact that different theories are not just more or less accurate representations mirroring an objective reality (Alvesson \& Kärreman 2007). Theories, as the effect of theorizing, provide different practical tools with which to represent and to interface with the reality represented, tools that are aligned with different purposes, interests and values, produced through tapping into different materialities in data.

The contribution also overcomes what is an insufficient degree of reflection on theorizing as a process (Suddaby 2014). For instance, an increasing awareness of the sociomaterial implications of theorizing and of the performative consequences of theories can help MOS to explicitly examine its own performative 'footprint', which should lead to reflecting on the negative impact of "academic navel gazing” (Reed \& Burrell 2019, p. 3). Investing resources, researching, writing, publishing and conferencing in questions not "worth answering" (Davis 2015, p. 314) creates a potential double negative impact. Aware of the capacity of theories to influence practices, first, there are the communities of theoretical practice that act as journal gatekeepers; second, there are potential users of theory in other actor networks of practice, less tolerant of the intricacies that tightly coupled actor networks can produce and more tolerant of solutions they can understand to problems that they think they understand. Organizational theories, in small ways, enable and restrict transformation of the world, not just the world of theory. Small wins, perhaps, but with Machado de Assis (1881 [1997]), we can conclude that theorizing, as a form of thinking errata, a constant production of new editions, each connected to predecessors, is ultimately destined for the book worms. All heated debate eventually turns to dust. The present contribution casts light on the processes that precede such reduction and does so by using organization theories to explain organization theorizing. 


\section{REFERENCES}

Abdallah, C., Denis, J.-L., \& Langley, A. 2011. Having your cake and eating it too : Discourses of transcendence and their role in organizational change dynamics. Journal of Organizational Change Management, 24(3).

Abend, G. 2008. The Meaning of 'Theory'. Sociological Theory, 26(2): 173-199.

Abrahamson, E. 1991. Managerial Fads and Fashions: The Diffusion and Rejection of Innovations. Academy of Management Review, 16: 586-612.

Alvesson, M., \& Gabriel, Y. 2013. Beyond formulaic research: in praise of greater diversity in organizational research and publications. Academy of Management Learning \& Education, 12: 245-263.

Alvesson, M., \& Kärreman, D. 2000. Varieties of Discourse: On the Study of Organizations through Discourse Analysis. Human Relations, 53: 1125-1149.

Alvesson, M., \& Kärreman, D. 2007. Constructing Mystery: Empirical Matters in Theory Development. Academy of Management Review, 32: 1265-1281.

Alvesson, M., \& Sandberg, J. 2011. Generating research questions through problematization. Academy of Management Review, 36(2): 247-271.

Alvesson, M., \& Sandberg, J. 2013. Has management studies lost its way? Ideas for more imaginative and innovative research. Journal of Management Studies, 50(1): 128152.

Alvesson, M., \& Spicer, A. 2018. Neo-Institutional Theory and Organization Studies: A MidLife Crisis? Organization Studies, online first 6/7/18.

Ancona, D. G., \& Bresman, H. 2007. X-teams: How to build teams that lead, innovate, and succeed: Harvard Business Press.

Antonacopoulou, E. P. 2010. Making the Business School More Critical: Reflexive Critique Based on Phronesis as a Foundation for Impact. British Journal of Management, 
21(s1): s6-s6.

Astley, W. G., \& Zammuto, R. F. 1992. Organization Science, Managers, and Language Games. Organization Science, 3: 443-460.

Austin, J. L. 1962. How to do things with words. Cambridge, MA: Harvard University Press

Bacharach, S. B. 1989. Organizational theories: some criteria for evaluation. Academy of Management Review, 14(4): 496-515.

Bakken, T., \& Hernes, T. 2006. Organizing is both a verb and a noun: Weick meets Whitehead. Organization Studies, 27(11): 1599-1616.

Barad, K. 2003. Posthumanist Performativity: Toward an Understanding of How Matter Comes to Matter. Signs, 28: 801-831.

Barnes, B. 1983. Social life as bootstrapped induction. Sociology, 17(4): 524-545.

Bartunek, J. M. 2020. Theory (What Is It Good For?). Academy of Management Learning \& Education.

Bazerman, M. H. 2005. Conducting influential research: the need for prescriptive implications. Academy of Management Review, 30: 25.

Bednarek, R., Paroutis, S., \& Sillince, J. 2017. Transcendence through Rhetorical Practices: Responding to Paradox in the Science Sector. Organization Studies, 38(1): 77-101.

Bennis, W. G., \& O'Toole, J. 2005. How business schools lost their way. Harvard business Review, 83: 96.

Berti, M. 2017. Elgar Introduction to Organizational Discourse Analysis. Cheltenham: Edward Elgar.

Bhaskar, R. 1975 [2008]. A realist theory of science. London: Routledge.

Birkinshaw, J., Healey, M. P., Suddaby, R., \& Weber, K. 2014. Debating the Future of Management Research, Journal of Management Studies, Vol. 51: 38-55.

Bort, S., \& Kieser, A. 2011. Fashion in Organization Theory: An Empirical Analysis of the 
Diffusion of Theoretical Concepts. Organization Studies, 32: 655-681.

Boxenbaum, E., \& Rouleau, L. 2011. New knowledge products as bricolage: Metaphors and scripts in organizational theory. Academy of Management Review, 36(2): 272-296.

Broad, W. J. 1981. The publishing game: getting more for less. Science, 211: 1137-1139.

Burns, T., \& Stalker, G. M. 1961. The management of innovation. London: Tavistock.

Burrell, G., \& Morgan, G. 1979. Sociological paradigms and organisational analysis. London, UK: Heinemann.

Byron, K., \& Thatcher, S. M. B. 2016. Editors' comments: "What I Know Now That I Wish I Knew Then"-Teaching theory and theory building. Academy of Management Review, 41(1): $1-8$.

Callon, M. 1995. Four models for the dynamics of science. In S. Jasanoff, G. E. Markle, J. C. Petersen, \& T. Pinch (Eds.), Handbook of Science and Technology Studies: 29-63. Thousand Oaks, Ca: SAGE.

Callon, M. 2007. What does it mean to say that economics is performative? In D. MacKenzie, F. Muniesa, \& L. Siu (Eds.), Do economists make markets? On the performativity of economics: 311-357. Princeton, NJ: Princeton University Press.

Cannella, A., \& Paetzold, R. 1994. Pfeffer's barriers to the advance of organizational science: A rejoinder. Academy of Management Review, 19(2): 331-341.

Carlsen, A., Clegg, S. R., \& Gjersvik, R. 2012. Idea Work: Lessons of the Extraordinary in Everyday Creativity. Oslo: Cappelen Damm Akademisk.

Clegg, S. R. 1989a. Frameworks of power. London, UK: SAGE.

Clegg, S. R. 1989b. Radical revisions: Power, discipline and organizations. Organization studies, 10(1): 97-115.

Coldevin, G. H., Carlsen, A., Clegg, S., Pitsis, T. S., \& Antonacopoulou, E. P. 2019. Organizational creativity as idea work: Intertextual placing and legitimating 
imaginings in media development and oil exploration. Human Relations, 72(8): $1369-1397$.

Corley, K. G., \& Gioia, D. A. 2011. Building theory about theory building: what constitutes a theoretical contribution? Academy of Management Review, 36(1): 12-32.

Cornelissen, J. P. 2005. Beyond Compare: Metaphor in Organization Theory. Academy of Management Review, 30: 751-764.

Cornelissen, J. P. 2017. Editor's comments: Developing propositions, a process model, or a typology? Addressing the challenges of writing theory without a boilerplate. Academy of Management Review, 42(1): 1-9.

Cunha, M. P., \& Putnam, L. L. 2019. Paradox theory and the paradox of success. Strategic Organization, 17(1): 95-106.

Cunha, M. P. E., Fortes, A., Gomes, E., Rego, A., \& Rodrigues, F. 2019. Ambidextrous leadership, paradox and contingency: evidence from Angola. The International Journal of Human Resource Management, 30(4): 702-727.

Czarniawska, B. 2017. Bruno Latour and Niklas Luhmann as organization theorists. European Management Journal, 35(2): 145-150.

D'Adderio, L., Glaser, V., \& Pollock, N. 2019. Performing Theories, Transforming Organizations: A Reply to Marti and Gond. Academy of Management Review, 44(3): 676-679.

D’Adderio, L., \& Pollock, N. 2014. Performing Modularity: Competing Rules, Performative Struggles and the Effect of Organizational Theories on the Organization. Organization Studies, 35(12): 1813-1843.

Davis, G. F. 2010. Do theories of organizations progress? Organizational Research Methods, 13(4): 690-709.

Davis, G. F. 2015. Celebrating Organization Theory: The After-Party. Journal of 
Management Studies, 52(2): 309-319.

Davis, M. S. 1971. That's interesting! Towards a phenomenology of sociology and a sociology of phenomenology. Philosophy of the Social Sciences, 1(2): 309-344.

DiMaggio, P. J., \& Powell, W. W. 1983. The Iron Cage Revisited: Institutional Isomorphism and Collective Rationality in Organizational Fields. American Sociological Review, 48: $147-160$.

Donaldson, L. 1987. Strategy And Structural Adjustment To Regain Fit And Performance: In Defence Of Contingency Theory, Journal of Management Studies, Vol. 24.

Donaldson, L. 1995. American anti-management theories of organization: A critique of paradigm proliferation. Cambridge: Cambridge University Press.

Donaldson, L. 1996. For positivist organization theory: proving the hard core. Thousand Oaks, CA: SAGE.

Donaldson, L. 2001. The contingency theory of organizations. Thousand Oaks, CA: SAGE.

Douglas, M. 1966. Purity and Danger: An Analysisof the Concepts of Pollution and Taboo. London, UK: Routledge.

Douglas, M. 1970. Natural Symbols: Explorations in Cosmology. London, UK: Routledge.

Douglas, M. 1986. How institutions think. Syracuse, NY: Syracuse University Press.

Eisenhardt, K. M. 1989. Building Theories from Case Study Research. Academy of Management Review, 14: 532-550.

Fama, E. F., \& Jensen, M. C. 1983. Agency problems and residual claims. The journal of law and Economics, 26(2): 327-349.

Farjoun, M. 2010. Beyond dualism: Stability and change as a duality. Academy of Management Review, 35(2): 202-225.

Ferraro, F., Pfeffer, J., \& Sutton, R. I. 2005. Economics language and assumptions: How theories can become self-fulfilling. Academy of Management Review, 30(1): 8-24. 
Fleck, L. 1935 [2012]. Genesis and development of a scientific fact. Chicago, IL: University of Chicago Press.

Fleming, P., \& Spicer, A. 2014. Power in management and organization science. The Academy of Management Annals, 8(1): 237-298.

Flyvbjerg, B. 2001. Making social science matter : why social inquiry fails and how it can succeed again. Oxford, UK: Cambridge University Press.

Folger, R., \& Turillo, C. J. 1999. Theorizing as the Thickness of Thin Abstraction. Academy of Management Review, 24(4): 742-758.

Foucault, M. 1977. Discipline and punish: the birth of the prison. New York, NY: Vintage Books.

Foucault, M. 1980. Power/knowledge: selected interviews and other writings, 1972-1977. New York, NY: Harvester Wheatsheaf.

Foucault, M. 1984. The history of sexuality, vol. I An Introduction. New York, NY: Vintage.

Frickel, S., \& Gross, N. 2005. A general theory of scientific/intellectual movements. American Sociological Review, 70(2): 204-232.

Frickel, S., \& Moore, K. 2006. The New Political Sociology of Science : Institutions, Networks, and Power. Madison, UNITED STATES: University of Wisconsin Press. Gabriel, Y. 2010. Organization studies: a space for ideas, identities and agonies. Organization Studies, 31(6): 757-775.

Garud, R., \& Gehman, J. 2019. Performativity: Not a Destination but an Ongoing Journey. Academy of Management Review, 44(3): 679-684.

Garud, R., Gehman, J., Kumaraswamy, A., \& Tuertscher, P. 2017. From the process of innovation to innovation as process. In A. Langley, \& H. Tsoukas (Eds.), $\boldsymbol{T h} \boldsymbol{e} \boldsymbol{S A G E}$ Handbook of Process Organizational Studies: 451-465. London: SAGE. 
Garud, R., Gehman, J., \& Tharchen, T. 2018. Performativity as ongoing journeys: Implications for strategy, entrepreneurship, and innovation. Long Range Planning, 51(3): 500-509.

Ghoshal, S. 2005. Bad Management Theories Are Destroying Good Management Practices. Academy of Management Learning \& Education, 4: 75.

Gioia, D. A., \& Pitre, E. 1990. Multiparadigm perspectives on theory building. Academy of Management Review, 15(4): 584-602.

Gond, J. P., Cabantous, L., Harding, N., \& Learmonth, M. 2016. What do we mean by performativity in organizational and management theory? The uses and abuses of performativity. International Journal of Management Reviews, 18(4): 440-463.

Gondo, M. B., \& Amis, J. M. 2013. Variations in practice adoption: The roles of conscious reflection and discourse. Academy of Management Review, 38(2): 229-247.

Grandori, A. 2001. Methodological options for an integrated perspective on organization. Human Relations, 54(1): 37-47.

Hambrick, D. C. 2007. The field of management's devotion to theory: Too much of a good thing? Academy of Management Journal, 50(6): 1346-1352.

Hannan, M. T., \& Freeman, J. 1984. Structural inertia and organizational change. American Sociological Review, 49(2): 149-164.

Hardy, C., \& Clegg, S. R. 1997. Relativity Without Relativism: Reflexivity in Post-Paradigm Organization Studies. British Journal of Management, 8: 5-17.

Hardy, C., Phillips, N., \& Clegg, S. R. 2001. Reflexivity in Organization and Management Theory: A Study of the Production of the Research `Subject. Human Relations, 54: $531-560$.

Hargadon, A. B., \& Douglas, Y. 2001. When innovations meet institutions: Edison and the design of the electric light. Administrative Science Quarterly, 46(3): 476-501. 
Hassard, J., \& Wolfram Cox, J. 2013. Can Sociological Paradigms Still Inform

Organizational Analysis? A Paradigm Model for Post-Paradigm Times. Organization Studies, 34(11): 1701-1728.

Heidegger, M. 1927. Being and Time (J. Stambaugh, Trans.). New York, NY: State Universtity of New York Press.

Jarzabkowski, P. A., \& Lê, J. K. 2017. We Have To Do This and That? You Must be Joking: Constructing and Responding to Paradox Through Humor. Organization Studies, 38(3-4): 433-462.

Judge, T. A., Cable, D. M., Colbert, A. E., \& Rynes, S. L. 2007. What Causes a Management Article to Be Cited: Article, Author, or Journal? Academy of Management Journal, 50: 491-506.

Keller, J., Loewenstein, J., \& Yan, J. 2017. Culture, Conditions and Paradoxical Frames. Organization Studies, 38(3-4): 539-560.

Kolpakov, A., \& Anguelov, L. G. 2020. Decision-making approaches to contracting out. Journal of Strategic Contracting and Negotiation, First Published April 17, 2020(https://doi.org/10.1177/2055563620918811).

Kuhn, T. S. 1970. The structure of scientific revolutions (2nd edition ed.). Chicago, IL: University of Chicago Press.

Lakatos, I. 1970. Falsification and the methodology of scientific research programmes. Criticism and the growth of knowledge, 4: 91-196.

Lakatos, I. 1978. The methodology of scientific research programmes (J. Worrall, Trans.). Cambridge: Cambridge University Press.

Lakoff, G., \& Johnson, M. 1980. Metaphors we live by. Chicago, IL University of Chicago Press.

Lamont, M. 2009. How Professors Think: Inside the Curious World of Academic 
Judgment. Cambridge, MA: Harvard University Press.

Lange, D., \& Pfarrer, M. D. 2017. Editors' comments: Sense and Structure--The Core Building Blocks of an AMR Article. Academy of Management Review, 42(3): 407416.

Latour, B. 1999. Pandora's hope: essays on the reality of science studies. Cambridge, MA: Harvard University Press.

Latour, B., \& Woolgar, S. 1979. Laboratory life: the social construction of scientific facts. Beverly Hills, CA: SAGE.

Law, J. 2008. Actor network theory and material semiotics. In B. S. Turner (Ed.), The new Blackwell companion to social theory: 141-158. New York, NY: John Wiley \& Sons. Lawrence, P. R., \& Lorsch, J. W. 1967. Organization and environment: managing differentiation and integration. Boston, MA: Harvard University.

Lê, J. K., \& Bednarek, R. 2017. Paradox in Everyday Practice. In W. K. Smith, M. W. Lewis, P. Jarzabkowski, \& A. Langley (Eds.), The Oxford Handbook of Organizational Paradox 490-509. Oxford: Oxford University Press.

Lewis, M. W. 2000. Exploring paradox: Toward a more comprehensive guide. Academy of Management Review, 25(4): 760-776.

Lewis, M. W., \& Grimes, A. J. 1999. Metatriangulation: Building Theory from Multiple Paradigms, Academy of Management Review, Vol. 24: 672-690.

Lewis, M. W., \& Smith, W. K. 2014. Paradox as a metatheoretical perspective: Sharpening the focus and widening the scope. Journal of Applied Behavioral Science, 50(2): 127-149.

Logue, D. M., Clegg, S., \& Gray, J. 2016. Social organization, classificatory analogies and institutional logics: Institutional theory revisits Mary Douglas. Human Relations, 69(7): 1587-1609. 
Lounsbury, M., \& Beckman, C. 2015. Celebrating Organization Theory, Journal of Management Studies, Vol. 52: 288-308.

Lüscher, L. S., \& Lewis, M. W. 2008. Organizational Change And Managerial Sensemaking: Working Through Paradox. Academy of Management Journal, 51(2): 221-240.

Machado de Assis, J. M. 1881 [1997]. The Posthumous Memoirs of Brás Cubas (G. Rabassa, Trans.). Oxford: Oxford University Press.

MacKenzie, D. 2006. Is economics performative? Option theory and the construction of derivatives markets. In D. MacKenzie, F. Muniesa, \& L. Siu (Eds.), Do Economists Make Markets?: On the Performativity of Economics: 54-86. Princeton, NJ: Princeton University Press.

Marti, E., \& Gond, J.-P. 2018. When do theories become self-fulfilling? exploring the boundary conditions of performativity, Academy of Management Review, Vol. 43: 487-508.

Marti, E., \& Gond, J.-P. 2019. How Do Theories Become Self-Fulfilling? Clarifying the Process of Barnesian Performativity. Academy of Management Review, 44(3): 686694.

Martin, J., Frost, P. J., \& O’Neill, O. A. 2006. Organizational culture: Beyond struggles for intellectual dominance. In S. R. Clegg, C. Hardy, T. B. Lawrence, \& W. R. Nord (Eds.), The SAGE Handbook of Organization studies: 725-753. London: SAGE. McHugh, P. 1970. On the failure of positivism. In J. D. Doulas (Ed.), Understanding Everyday Life: 320-336. London, UK: Routledge.

McKinley, W., Mone, M. A., \& Moon, G. 1999. Determinants and development of schools in organization theory. Academy of Management Review, 24(4): 634-648.

Mehrpouya, A., \& Willmott, H. 2018. Making a Niche: The Marketization of Management Research and the Rise of "Knowledge Branding”. Journal of Management Studies, 
Accepted Author Manuscript.

Michailova, S., Piekkari, R., Plakoyiannaki, E., Ritvala, T., Mihailova, I., \& Salmi, A. 2014. Breaking the silence about exiting fieldwork: a relational approach and its implications for theorizing. Academy of Management Review, 39(2): 138-161.

Mills, C. W. 1980. On intellectual craftsmanship (1952). Society, 17(2): 63-70.

Morgan, G. 2006. Images of organization. Thousand Oaks, CA: SAGE.

Mueller, F., \& Whittle, A. 2011. Translating management ideas: A discursive devices analysis. Organization Studies, 32(2): 187-210.

Oswick, C., Fleming, P., \& Hanlon, G. 2011. From borrowing to blending: rethinking the process of organizational theory building. Academy of Management Review, 36(2): $318-337$.

Papachroni, A., Heracleous, L., \& Paroutis, S. 2016. In pursuit of ambidexterity: Managerial reactions to innovation-efficiency tensions. Human Relations, 69(9): 1791-1822.

Parmigiani, A., \& Howard-Grenville, J. 2011. Routines revisited: Exploring the capabilities and practice perspectives. Academy of Management Annals, 5(1): 413-453.

Paton, S., Chia, R., \& Burt, G. 2013. Relevance or 'relevate'? How university business schools can add value through reflexively learning from strategic partnerships with business. Management Learning.

Peng, K., \& Nisbett, R. E. 1999. Culture, dialectics, and reasoning about contradiction. American Psychologist, 54(9): 741.

Peters, T., \& Bogner, W. C. 2002. Tom Peters on the Real World of Business. Academy of Management Executive, 16: 40-44.

Pezet, E. 2012. Pacifying the social: Creating the French citizen worker, 1968-1975. Management \& Organizational History, 7(1): 61-71.

Pfeffer, J. 1993. Barriers to the Advance of Organizational Science: Paradigm Development 
as a Dependent Variable, Academy of Management Review, Vol. 18: 599-620.

Pfeffer, J. 2007. A Modest Proposal: How We Might Change the Process and Product of Managerial Research. Academy of Management Journal, 50: 1334-1345.

Pfeffer, J. 2014. The management theory morass: Some modest proposals. In J. A. Miles (Ed.), New Directions in Management and Organization Theory: 457-468.

Newcastle-upon-Tyne: Cambridge Scholars Publishing.

Pfeffer, J., \& Sutton, R. I. 2006. Hard Facts, Dangerous Half-Truths, and Total Nonsense: Profiting from Evidence-Based Management. Harvard, MA: Harvard Business School Press.

Pickering, A. 1993. The mangle of practice: Agency and emergence in the sociology of science. American Journal of Sociology, 99(3): 559-589.

Poole, M. S., \& van de Ven, A. H. 1989. Using Paradox to Build Management and Organization Theories. Academy of Management Review, 14(4): 562-578.

Popper, K. R. S. 1959. The logic of scientific discovery. London: Hutchinson.

Pugh, D. S., \& Hickson, D. J. 1976. Organizational structure in its context: The Aston Programme. Farnborough, Hants.: Saxon House.

Qiu, J., Donaldson, L., \& Luo, B. N. 2012. The Benefits of Persisting With Paradigms in Organizational Research. Academy of Management Perspectives, 26(1): 93-104.

Reed, M., \& Burrell, G. 2019. Theory and organization studies: The need for contestation. Organization Studies, 40(1): 39-54.

Rindova, V. 2008. Editor's Comments: Publishing Theory When You Are New to the Game. Academy of Management Review, 33(2): 300-303.

Rorty, R. 1979. Philosophy and the Mirror of Nature. Princeton, NJ: Princeton University Press.

Sandberg, J., \& Alvesson, M. 2011. Ways of constructing research questions: gap-spotting or 
problematization? Organization, 18(1): 23-44.

Sandberg, J., \& Tsoukas, H. 2011. Grasping the logic of practice: theorizing through practical rationality. Academy of Management Review, 36: 338.

Schad, J., Lewis, M. W., \& Smith, W. K. 2019. Quo vadis, paradox? Centripetal and centrifugal forces in theory development. Strategic Organization, 17(1): 107-119.

Schütz, A. 1945. On Multiple Realities. Philosophy and Phenomenological Research, 5: $533-576$.

Schütz, A. 1953. Common-Sense and Scientific Interpretation of Human Action. Philosophy and Phenomenological Research, 14: 1-38.

Schwarz, G. M., Cummings, C., \& Cummings, T. G. 2017. Devolution of researcher care in organization studies and the moderation of organizational knowledge. Academy of Management Learning \& Education, 16(1): 70-83.

Shapira, Z. 2011. "I've Got a Theory Paper-Do You?": Conceptual, Empirical, and Theoretical Contributions to Knowledge in the Organizational Sciences. Organization Science, 22(5): 1312-1321.

Sillince, J. A. A. 2005. A Contingency Theory of Rhetorical Congruence. Academy of Management Review, 30: 608-621.

Simon, H. 1962. The architecture of complexity. Proceedings of the American Philosophical Society, 106(6): 467-482.

Smets, M., Jarzabkowski, P., Burke, G. T., \& Spee, P. 2015. Reinsurance Trading in Lloyd's of London: Balancing Conflicting-Yet-Complementary Logics in Practice. Academy of Management Journal, 58(3): 932.

Smith, W. K. 2014. Dynamic decision making: A model of senior leaders managing strategic paradoxes. Academy of Management Journal, 57(6): 1592-1623.

Smith, W. K., \& Lewis, M. W. 2011. Toward a theory of paradox: A dynamic equilibrium 
model of organizing. Academy of Management Review, 36(2): 381-403.

Starbuck, W. H. 2005. How Much Better Are the Most-Prestigious Journals? The Statistics of Academic Publication. Organization Science, 16: 180-200.

Suchman, M. C. 1995. Managing legitimacy: Strategic and institutional approaches. Academy of Management Review, 20(3): 571-610.

Suddaby, R. 2014. Editor's Comments: Why Theory? Academy of Management Review, 39(4): 407-411.

Sutton, R. I., \& Staw, B. M. 1995. What theory is not. Administrative Science Quarterly, 40(3): 371-384.

Thornton, P. H., Ocasio, W., \& Lounsbury, M. 2012. The institutional logics perspective: A new approach to culture, structure, and process. Oxford, UK: Oxford University Press.

Tourish, D. 2020. The Triumph of Nonsense in Management Studies. Academy of Management Learning \& Education, 19(1): 99-109.

Tracy, S. J. 2004. Dialectic, contradiction, or double bind? Analyzing and theorizing employee reactions to organizational tension. Journal of Applied Communication Research, 32(2): 119-146.

Tsang, E. W. K., \& Ellsaesser, F. 2011. How contrastive explanation facilitates theory building. Academy of Management Review, 36(2): 404-419.

Tsoukas, H. 2017. Don't Simplify, Complexify: From Disjunctive to Conjunctive Theorizing in Organization and Management Studies. Journal of Management Studies, 54(2): 132-153.

Tushman, M. L., O'Reilly, C. A., Fenollosa, A., Adam, M. K. A. M., \& McGrath, D. 2007. Relevance and Rigor: Executive Education as a Lever in Shaping Practice and Research. Academy of Management Learning \& Education, 6: 345. 
Üsdiken, B., \& Pasadeos, Y. 1995. Organizational analysis in North America and Europe: A comparison of co-citation networks. Organization Studies, 16(3): 503-526.

Van Maanen, J. 1989. Some notes on the importance of writing in organization studies. Paper presented at the Harvard Business School Research Colloquium.

Van Maanen, J. 1995. Style As Theory. Organization Science, 6(1): 133-143.

Vonderembse, M. A., Uppal, M., Huang, S. H., \& Dismukes, J. P. 2006. Designing supply chains: Towards theory development. International Journal of production economics, 100(2): 223-238.

Weaver, G. R., \& Gioia, D. A. 1994. Paradigms lost: Incommensurability vs structurationist inquiry. Organization Studies, 15(4): 565.

Weber, M. 1922 [1978]. Economy and society: an outline of interpretive sociology. Berkeley, CA: University of California Press.

Weick, K. E. 1979. The Social Psychology of Organizing (2 ed.). Reading, MA: AddisonWesley.

Weick, K. E. 1989. Theory Construction as Disciplined Imagination. Academy of Management Review, 14: 516-531.

Weick, K. E. 1995a. Sensemaking in organizations. Thousand Oaks, CA: SAGE.

Weick, K. E. 1995b. What theory is not, theorizing is. Administrative Science Quarterly, 40(3): 385-390.

Weick, K. E. 1999. Conclusion: Theory Construction as Disciplined Reflexivity: Tradeoffs in the 90s. Academy of Management Review, 24(4): 797-806.

Weick, K. E. 2001. Gapping the Relevance Bridge: Fashions Meet Fundamentals in Management Research. British Journal of Management, 12: S71-S71.

Weick, K. E., Sutcliffe, K. M., \& Obstfeld, D. 2005. Organizing and the process of sensemaking. Organization Science, 16: 409-421. 
Whetten, D. A. 1989. What Constitutes A Theoretical Contribution? Academy of Management Review, 14(4): 490-495.

Wittgenstein, L. 1958. Philosophical investigations (G. E. M. Anscombe, Trans.). Oxford, UK: Blackwell.

Zietsma, C., Groenewegen, P., Logue, D. M., \& Hinings, C. R. 2017. Field or fields? Building the scaffolding for cumulation of research on institutional fields. Academy of Management Annals, 11(1): 391-450. 
Fig 1 Organizing processes and paradoxical tensions within research programs

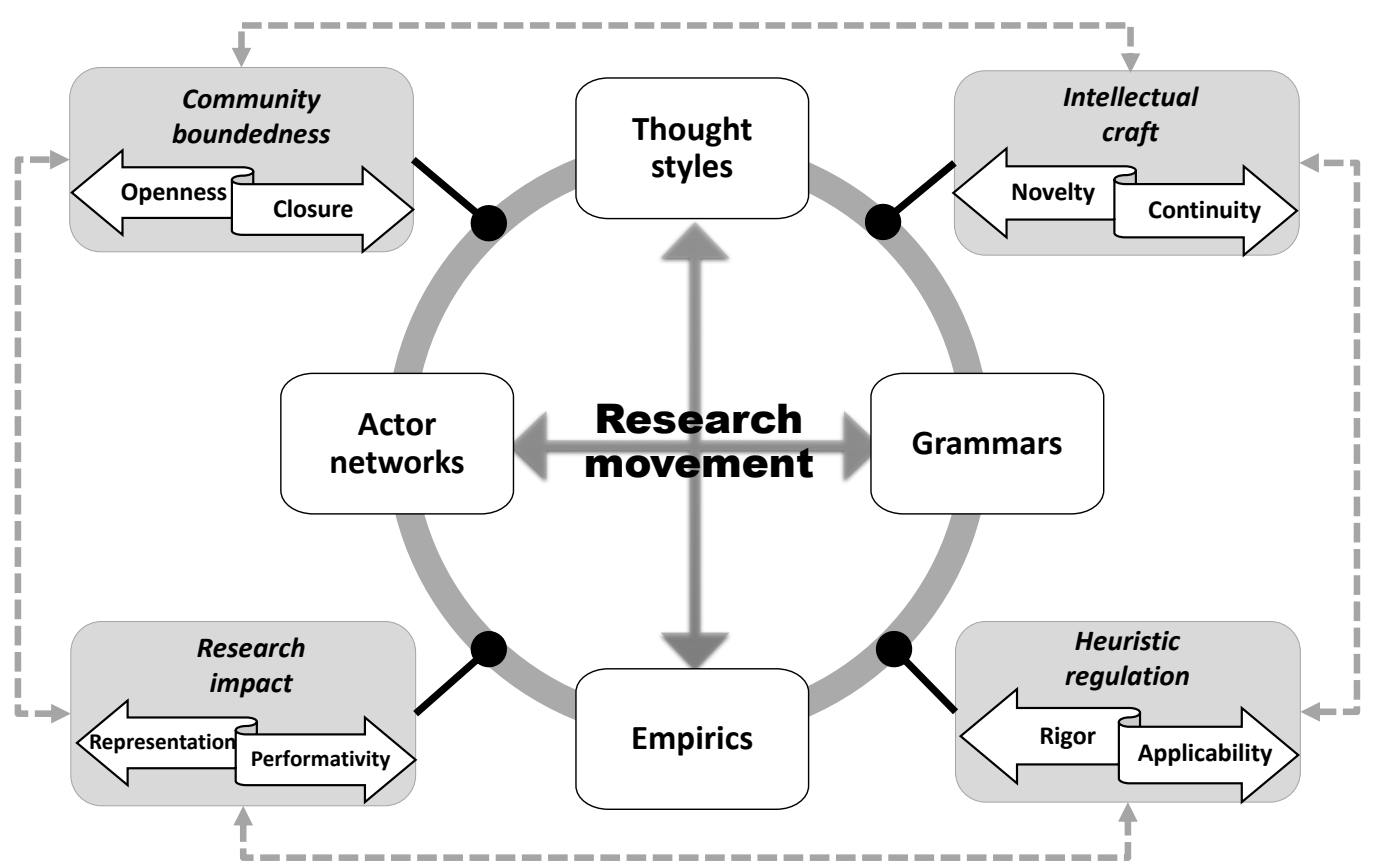


Stewart Clegg (stewart.clegg@uts.edu.au) is Distinguished Professor in Management at UTS Business School, University of Technology Sydney. He received his Ph.D. in management from Bradford University and also holds doctoral degrees from Umeå and the University of Technology Sydney. His research is substantively wideranging but invariably centered on power relations.

Miguel Pina e Cunha (miguel.cunha@novasbe.pt) is the Fundação Amélia de Mello Professor at Nova School of Business and Economics, Universidade Nova de Lisboa. He received his Ph.D. in management from Tilburg University. His research focuses on organization as process and paradox.

Marco Berti (marco.berti@uts.edu.au) is Senior Lecturer in Management at UTS Business School, University of Technology Sydney. He received his Ph.D. in management from the University of Technology Sydney. His research focuses on organizational paradoxes and tensions, critical themes, and the role of power and discourse in organizations. 